\title{
Predisposing conditions for bacterial meningitis in children: what radiologists need to know
}

\author{
Sota Masuoka ${ }^{1,4}$ (ए) Osamu Miyazaki ${ }^{1} \cdot$ Hiroaki Takahashi ${ }^{2} \cdot$ Yoshiyuki Tsutsumi $^{1} \cdot$ Takashi Hiyama $^{3}$. \\ Masayuki Kitamura ${ }^{1} \cdot$ Reiko Okamoto $^{1} \cdot$ Mikiko Miyasaka $^{1} \cdot$ Manabu Minami ${ }^{4} \cdot$ Shunsuke Nosaka ${ }^{1}$
}

Received: 7 July 2021 / Accepted: 13 August 2021 / Published online: 25 August 2021

(c) The Author(s) 2021

\begin{abstract}
A variety of underlying diseases can predispose infants and children to bacterial meningitis (BM). For the diagnosis, treatment, and prevention of its recurrence, radiologists should be familiar with its predisposing conditions so that they can suggest the appropriate imaging approach. Predisposing conditions of BM can be broadly classified into two categories: infection spread from the adjacent tissue to the cerebrospinal fluid (CSF) space and immunodeficiency. Diseases in the former category are further divided according to regardless of whether there is a structural defect between the CSF space and the adjacent tissue. When a structural defect is suspected in a patient with BM, computed tomography (CT) of the head and magnetic resonance (MR) imaging are first-line imaging examinations. Radionuclide cisternography should be implemented as a second-line step to identify the CSF leak site. In patients with suspected parameningeal infection without any structural defect, such as sinusitis or otitis media/mastoiditis, CT or MR images can identify not only the disease itself but also the associated intracranial complications. The purpose of this article is to discuss the diagnostic approach and imaging findings associated with the variety of conditions predisposing patients to recurrent BM, focusing on the role of radiology in their management.
\end{abstract}

Keywords Pediatrics $\cdot$ Bacterial infections $\cdot$ Meningitis $\cdot$ Multidetector computed tomography $\cdot$ Magnetic resonance imaging

This article was presented in part at the 105th annual meeting of the Radiological Society of North America (RSNA) in Chicago, 2019 (exhibit space number: PD103-ED-X). It received a certificate of merit.

Sota Masuoka

m.sohta.1987@gmail.com

1 Department of Diagnostic Radiology, National Center for Child Health and Development, 2-10-1 Okura, Setagaya-ku, Tokyo 157-8535, Japan

2 Department of Diagnostic Radiology, Mayo Clinic Minnesota, 200 First St. SW, Rochester, MN 55905, USA

3 Department of Diagnostic Radiology, National Cancer Center Hospital East, 6-5-1 Kashiwanoha, Kashiwa, Chiba 277-8577, Japan

4 Department of Diagnostic and Interventional Radiology, Faculty of Medicine, University of Tsukuba, 1-1-1, Tennoudai, Tsukuba, Ibaraki 305-8575, Japan

\section{Introduction}

Bacterial meningitis (BM) is an inflammation of the meninges (affecting the pia, arachnoid, and subarachnoid space) in response to a bacterial infection [1]. It is a medical emergency associated with a high mortality rate and incidence of neurological sequelae, if untreated. Thus, early diagnosis and the prompt initiation of empirical antimicrobial treatment are crucial. Popular causative organisms in children include Haemophilus influenzae type b (Hib), Streptococcus pneumoniae, and Neisseria meningitides. The widespread use of the Hib conjugate vaccine and the heptavalent pneumococcal conjugate vaccine (PCV7) has virtually eradicated meningitis caused by these organisms in many high-income countries [1]. As a result, the prevalence of bacterial meningitis in patients with predisposing conditions such as anatomical abnormalities, has increased. Recurrent $\mathrm{BM}$ is defined as a second episode of meningitis caused by a different pathogen than the one in the prior infection or occurring more than 3 weeks after the resolution of the 
prior episode [2,3]. Approximately $75 \%$ of the cases of $\mathrm{BM}$ occur in children under 5 years of age mainly due to the immature development of their immune system [1, 4-6]. A total of $1.3 \%$ of children with BM who underwent inpatient care had a recurrent episode [7, 8]. A predisposing condition for recurrent BM could be identified in $39 \%$ of patients [3]. Early diagnosis of these predisposing conditions is crucial for preventing recurrence of BM and improving the prognosis of the affected individuals. Therefore, the role of the radiological examination is critical in searching for these predisposing conditions in addition to assessing the complications of BM. In this article, the classification of the predisposing conditions for recurrent BM in children is described, along with the diagnostic approaches for each disorder.

\section{Management of children with suspected BM}

The management algorithm of the initial evaluation of a patient suspected of having BM is shown in Fig. 1. A prompt and accurate diagnosis followed by an empirical antimicrobial treatment is important in patients with suspected BM [9]. Cerebrospinal fluid (CSF) analysis by lumbar puncture allows for the confirmation of BM, and a radiological examination generally plays an auxiliary role in the initial evaluation $[1,9,10]$. Computed tomography (CT) and magnetic resonance (MR) images of the head are used to confirm existing conditions that could be contraindications for a lumbar puncture (i.e., a central nervous system mass, Chiari malformation type I, or other causes of increased intracranial pressure) [9]. Additional neuroimaging can be carried out in order to identify and monitor complications associated with meningitis, such as hydrocephalus, empyema, abscess, cerebritis, venous occlusion, and ischemia. Further, radiological investigations are indicated in patients who show evidence of predisposing conditions that may trigger BM. Predisposing conditions existing in the head and neck regions may be incidentally identified on neuroimaging acquired during the initial evaluation for BM. Therefore, initial radiological findings of patients with suspected BM should be well scrutinized.

\section{Classification and diagnostic approach for predisposing conditions associated with recurrent $\mathrm{BM}$}

The classification and diagnostic approach for each predisposing condition for recurrent BM are shown in Table 1. Predisposing conditions for recurrent BM can be broadly classified into two categories: (1) infection spread from the adjacent tissue to the CSF space and (2) immunodeficiency [7]. The disease entities in the former category are further

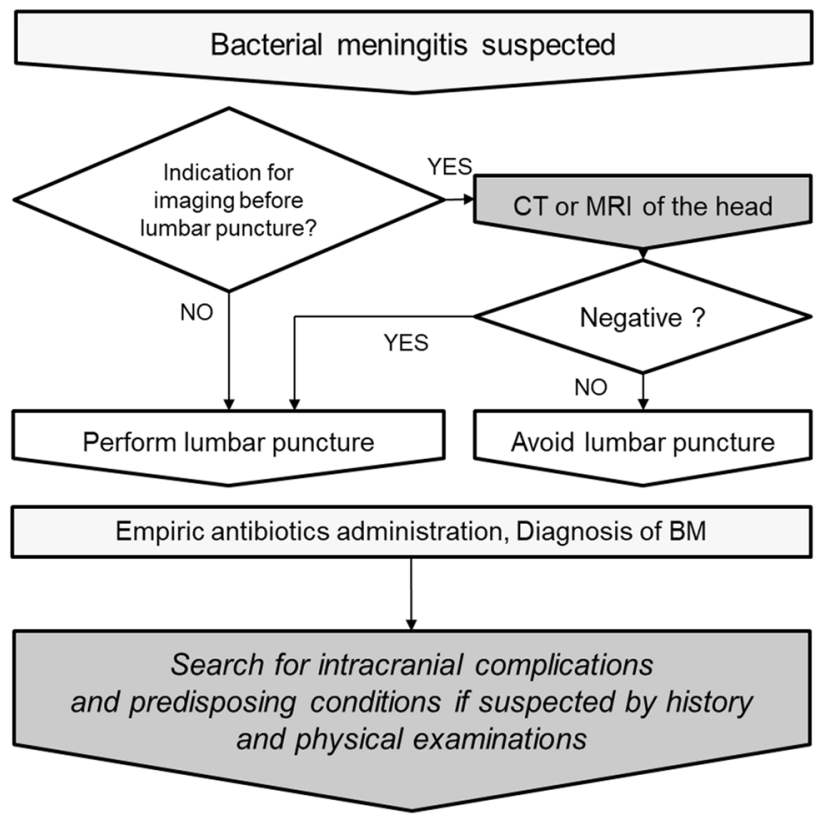

Fig. 1 The management algorithm of the initial evaluation for suspected bacterial meningitis (BM). Cerebrospinal fluid analysis by lumbar puncture enables the confirmation of $\mathrm{BM}$, and computed tomography (CT) or magnetic resonance (MR) images of the head are primarily used to confirm existing conditions that could be contraindications for a lumbar puncture (i.e., a central nervous system mass, Chiari malformation type I, or another cause of increased intracranial pressure). Furthermore, additional neuroimaging is carried out to identify complications and predisposing conditions associated with BM. Initial radiological imaging for BM should be critically evaluated since predisposing conditions existing in the head and neck regions could be incidentally identified in the images acquired for the initial evaluation of BM

divided according to whether there is a structural defect between the CSF space and the adjacent tissue. A predisposing condition with a structural defect (59\%) could either be congenital (i.e., spinal dermal sinus tract (DST), inner ear malformation, and skull base cephalocele) or acquired (i.e., skull base trauma). Parameningeal infections without a structural defect (5\%) primarily include sinusitis, otitis media, and mastoiditis, in which infections can spread continuously through the bony structure of the skull or via the hematogenous route. Immunodeficiency (36\%) predisposing to recurrent $\mathrm{BM}$ ranges from congenital to acquired diseases $[2,3,7]$.

Non-radiological examinations, including a patient's medical history, physical examinations, and laboratory examinations, provide important clinical clues informing the identification of predisposing conditions for recurrent BM [7].

Radiological examinations should be implemented for further assessment once a predisposing condition is suspected after non-radiological examinations. In patients with a suspected DST, spinal ultrasound (US) and MR imaging are 
I


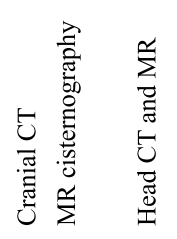
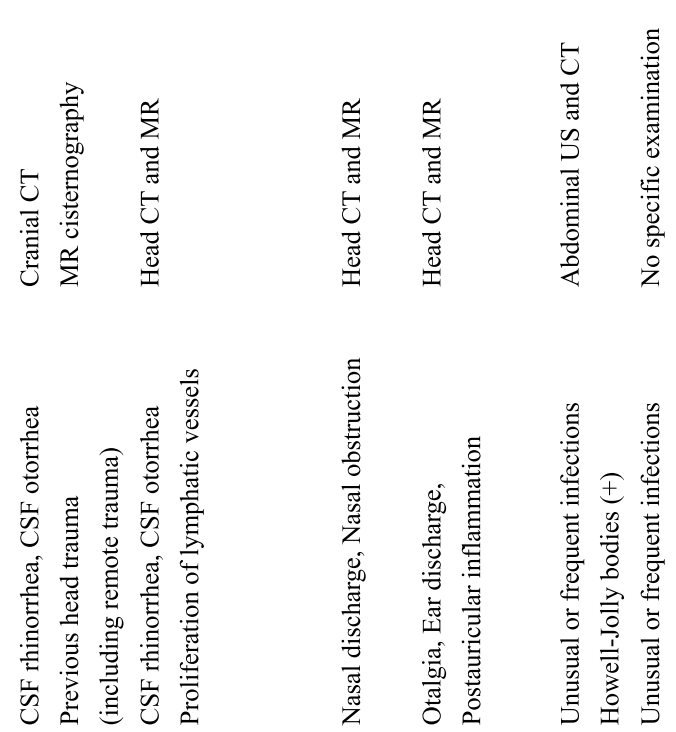

$\lessgtr$
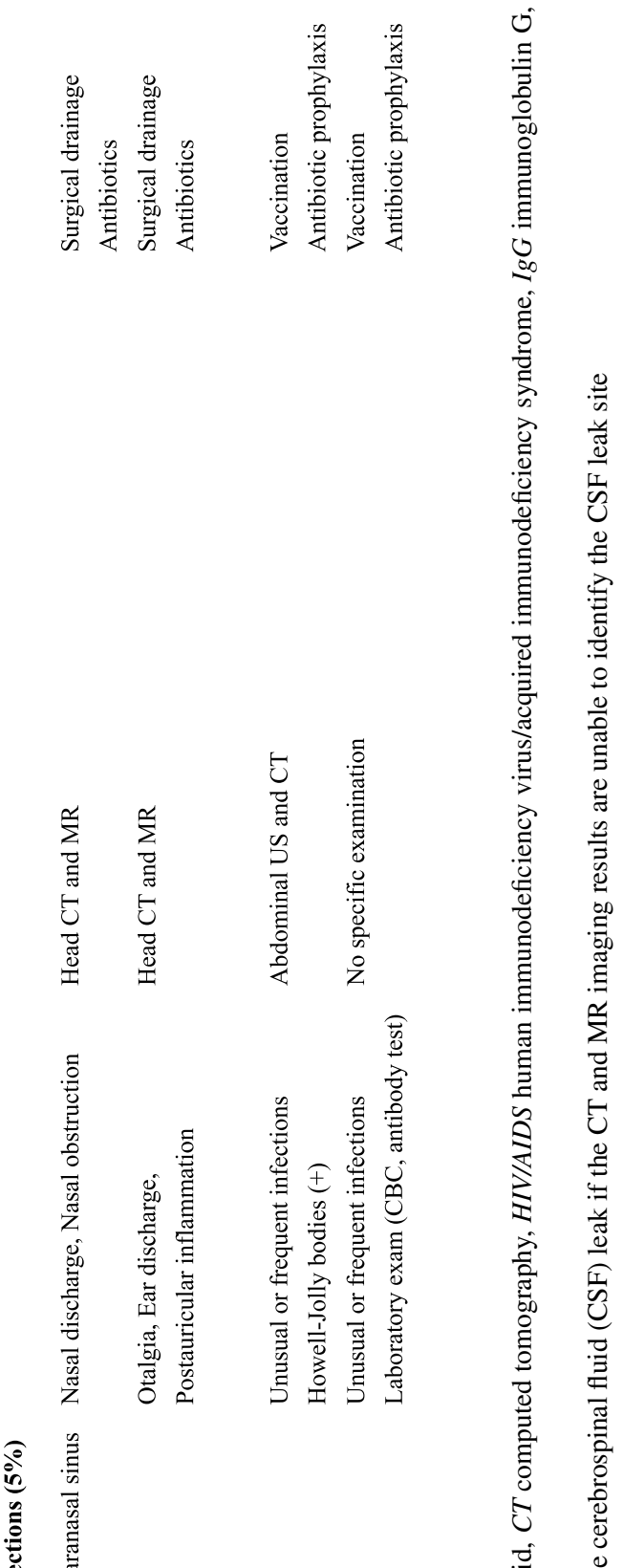
useful to visualize associated intraspinal abnormalities (i.e., tethered spinal cord and dermoid/epidermoid tumor) [11, 12]. In patients with suspected sinusitis and otitis media/mastoiditis, CT or MR images may also identify any associated intracranial diseases (subdural/intracranial abscess, venous thrombus) $[13,14]$. When a structural defect is suspected in a patient with a CSF leak, CT including CT cisternography or MR imaging are first-line imaging examinations. CT images provide the necessary spatial resolution to reveal even tiny skull base and inner ear malformations or defects. MR cisternography using a steady-state free precession technique allows for multiplanar reformats and facilitates the localization of the actual site of the CSF leak and detection of encephalocele or meningoencephalocele. Herniation of brain parenchyma or meninges through the bone defect could be easily visualized on MR images [15-17]. Invasive radiological examinations, including radionuclide cisternography, should be implemented as a second-line step if the noninvasive images are unable to identify the CSF leak site. Radionuclide cisternography using technetium-99 m-labeled diethylenetriaminepentaacetic acid can diagnose the CSF leak. Radionuclide cisternography involves the intrathecal administration of the radiotracer, followed by acquisition of the images [16]. The accumulation of the radiotracer in the nasal cavity or nasopharynx points to the presence of a CSF fistula $[15,16]$. Underlying immunodeficiency is mostly diagnosed clinically, and radiological examination plays a lesser role in this entity compared with the former categories. However, recurrent BM is sometimes accompanied by asplenia that can be diagnosed by abdominal US or CT images.

A treatment plan should be considered for predisposing conditions, along with antibiotic therapy for the BM itself. Surgical intervention should be carried out for diseases with structural defects. Sinusitis or otitis media/mastoiditis accompanying a parameningeal infection should be treated with surgical drainage. Patients with immunodeficiency should receive appropriate vaccinations and prophylactic antibiotics [7].

The following sections describe the detailed clinical features and imaging approach for each disease based on the classifications in Table 1.

\section{Infection spread from the adjacent tissue to the CSF space with a structural defect: congenital structural defect}

\section{Spinal dermal sinus tract (DST)}

\section{Clinical features}

DSTs are epithelium-lined tracts extending from the skin surface to the intradural space that occur in approximately one in every 2500 live births [18]. DSTs result from the incomplete separation of the cutaneous ectoderm from the underlying neuroectoderm between the third and eighth week of gestation. The tracts may terminate in the dura, spinal cord, conus medullaris, or filum terminale. The tracts are predominantly located in the lumbosacral region and, less commonly, in the occipital region, typically along the midline of the neuroaxis $[11,12,18]$.

Recurrent BM may occur due to the spread of the pathogen via the DST from the skin $[7,19]$. E. coli is the most common causative pathogen for recurrent $\mathrm{BM}$ in patients with a DST, most likely due to secondary to fecal contamination into the lumbosacral tract [6]. Inspection of the dermis is useful to assess the presence of a DST. Typical dermal findings in patients with a DST include a large and asymmetric dimple at the ostium that is remote from the anus. The overlying skin may show signs of an angiomatous lesion, abnormal pigmentation, skin tag, and hypertrichosis. Subcutaneous lipomas may be found around the ostium of a DST. If the local infection is associated with a DST, erythema and induration may be observed $[12,18,19]$. Approximately half of all DSTs are associated with dermoid or epidermoid tumors. It has also been noted that aseptic recurrent meningitis can occur due to the rupture of the dermoid or epidermoid into the CSF space [18-20].

\section{Management}

A DST associated with recurrent meningitis should be managed with appropriate antibiotics therapy followed by surgical excision of the tract [20]. Complete removal of the tract is necessary to prevent the repeated entry of the pathogen into the CSF space. Detethering of the tethered spinal cord and removal of the dermoid or epidermoid are also necessary if they are associated with the DST.

\section{Radiological assessment}

A spinal US can be performed as a first-line examination for the evaluation of the spinal cord in newborns or infants under the age of 6 months with a DST to visualize the tract and intraspinal lesion [12, 19, 21, 22]. Spinal MR imaging is superior in detectability for not only the DST itself but also its associated anomalies compared to the spinal US. Therefore, spinal MR imaging should be performed when a physical examination indicates the potential presence of a DST [11, 21] (Fig. 2).

A low conus medullaris is observed in $79 \%$ of patients with a DST. Intraspinal tumors, including spinal lipoma, dermoid and epidermoid, are associated with a DST. Dermoid and epidermoid tumors are commonly located at the 
intraspinal end of tracts, although they can be found at any location along with the DST [18].

Gadolinium-enhanced spinal MR imaging is useful to detect inflammatory changes associated with a DST [23, 24]. The peripheral enhancement of the tract and spinal cord can be observed in meningitis associated with the DST (Fig. 3). An intramedullary and extramedullary abscess may sometimes accompany BM. An intraspinal abscess can be seen as a peripheral enhancing mass lesion and can mimic infected dermoid or epidermoid tumors (Fig. 3). In addition, both entities show strong diffusion restriction. Therefore, radiologists should be aware that an underlying intraspinal tumor may be missed on MR imaging in patients with an intraspinal infection. In such cases, it is recommended to take a follow-up MR image to confirm the presence of the tumor after the meningitis is resolved.

\section{Inner ear malformation}

\section{Clinical features}

Congenital inner ear malformations result from a genetic disorder or a maternal infection during fetal development
$[25,26]$. Inner ear malformations are classified based on the time of developmental arrest of the inner ear, and the severity of the disease is correlated with the time of arrest. Various inner ear malformations may result from developmental arrest between the third and seventh gestational week [27]. A type I incomplete partition resulting from the cochlear development arrest in the fifth week is less well differentiated than a type II incomplete partition (Mondini deformity) that results from developmental arrest in the seventh week [27]. A type II incomplete partition is the most common type of cochlear malformation, accounting for $50 \%$ of all cochlear deformities [27, 28]. A type II incomplete partition is characterized by a cochlea with a normal basal turn and cystic apex and an enlarged vestibule. A type I incomplete partition shows a separated cystic cochlea and vestibule [27].

Congenital inner ear malformations account for $15 \%$ of all patients with recurrent BM [7]. The most common pathogen responsible for BM is $S$. pneumoniae in patients with inner ear malformations. Initial episodes of BM due to inner ear malformations often occur in the first decade of life [29]. Recent widespread use of newborn hearing screening has improved the rate of early diagnosis of inner ear malformations that can cause
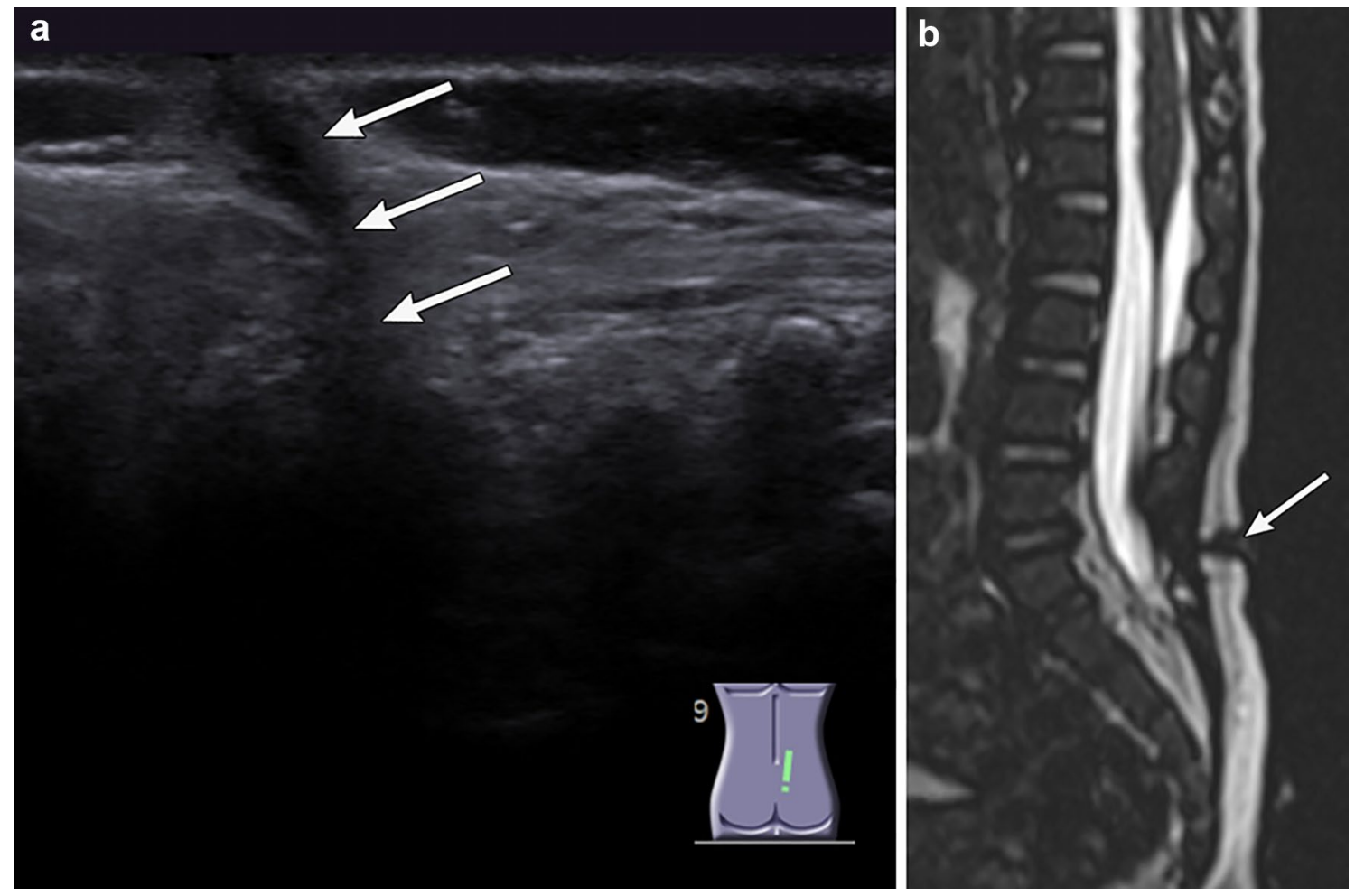

Fig. 2 A spinal dermal sinus tract (DST) in a 1-year-old boy with bacterial meningitis (BM). A sacral dimple with cutaneous stigmata was found at 1 month. Initial spinal ultrasound (US) performed for screening purposes at 1 month did not detect any obvious abnormalities. The patient was admitted due to BM, and spinal US was per- formed again when the patient was 1 year old. a US at age 1 year shows a continuous tract to the spinal canal from the skin (white arrows). b Sagittal T2-weighted magnetic resonance image clearly shows a DST connected to a skin dimple from the dural sac (white arrow) 

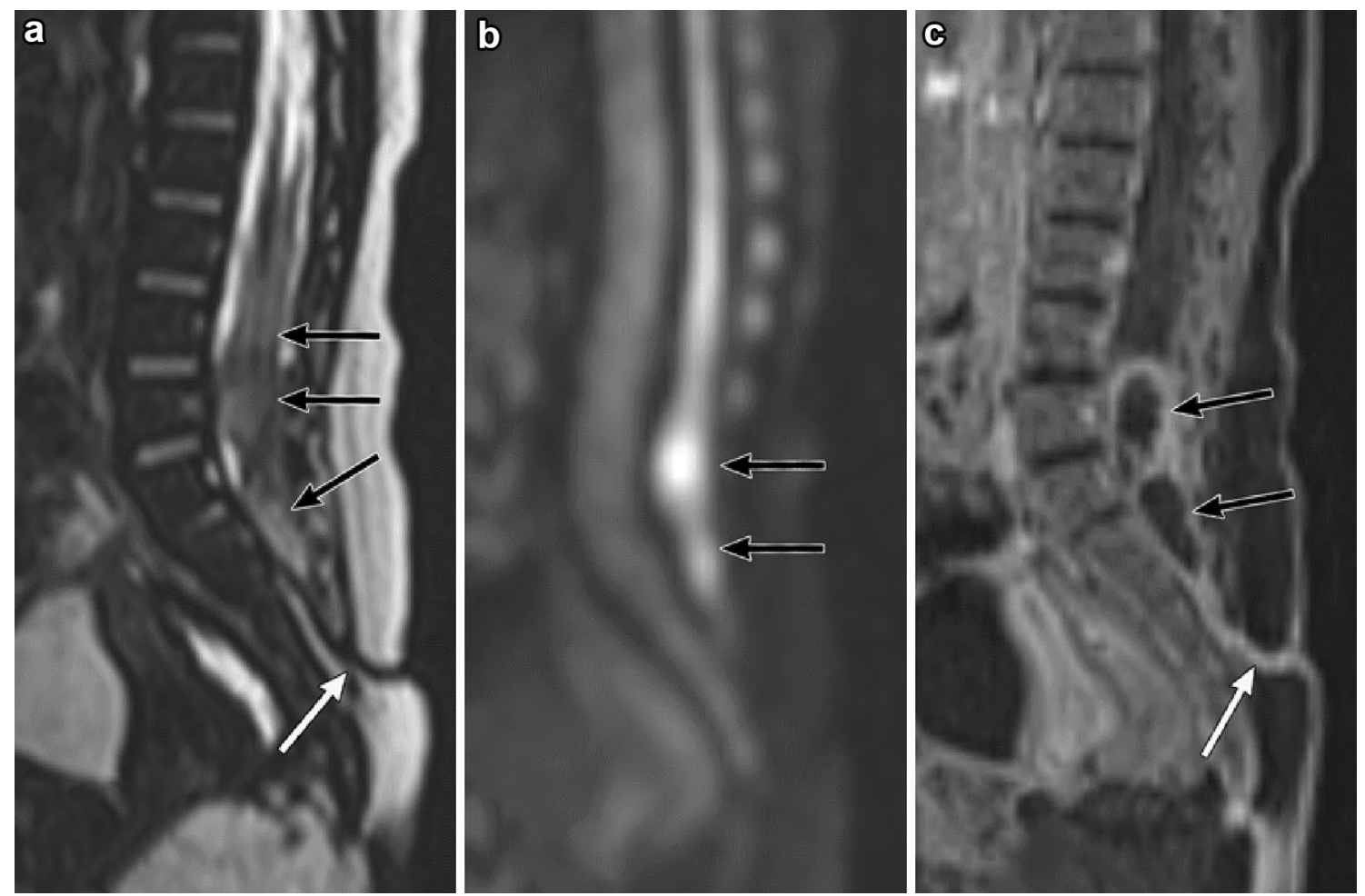

Fig. 3 A spinal dermal sinus tract (DST) in a 3-month-old girl with bacterial meningitis (BM). A sacral dimple was first noted during her hospitalization for BM. a Sagittal T2-weighted magnetic resonance (MR) image shows a low conus medullaris. The caudal end of the spinal cord is tethered by a DST (white arrow). The spinal cord is thickened, and hyperintense tumor-like structures are observed in the dural sac (black arrows). b Diffusion-weighted image shows the tumor-like structures with diffusion restriction in the dural sac (black

sensorineural hearing loss. In some cases, however, hearing loss remains unrecognized and recurrent $\mathrm{BM}$ can lead to a diagnosis of inner ear malformation [7, 30]. BM itself can cause a temporary hearing impairment that could be a potential differential diagnosis for underlying inner ear malformations [7, 31].

BM results from two fistulous connections: (1) between the internal auditory canal and the inner ear and (2) between the inner ear and the middle ear (Fig. 4). It is likely that a fistula of the cribriform area between the cochlea and internal auditory canal is a site of CSF leak in the medial side of the inner ear in patients with inner ear malformations. CSF leaks into the middle ear from the inner ear, can occur at the oval window due to the fistula in the region of the stapes footplate [27, 32, 33]. Patients with a cochlear implant are known to have an increased risk of BM due to the iatrogenic connection between the inner and middle ears. A CSF leak is a more common surgical complication in cases of type I incomplete partition (64\%) than in cases of type II incomplete partition $(37 \%)[26,34]$. arrows). c Gadolinium-enhanced fat-suppressed T1-weighted MR image shows that the tract (white arrow) and rim of the tumor-like structures (black arrows) are enhanced. The differential diagnoses at this point include an infected dermoid or epidermoid and intraspinal abscess in the dural sac. Surgical resection of the DST and untethering of the spinal cord were performed. An intraspinal abscess and a dermoid tumor in the dural sac were also resected during surgery

\section{Management}

Surgical closure of the fistula from the subarachnoid space to the middle ear is the definitive treatment for the prevention of recurrent BM [29]. Pneumococcal vaccinations are also useful in preventing recurrent meningitis, although surgical treatment is indicated [31].

\section{Radiological assessment}

CT and MR imaging of the temporal bones are used to reveal and assess inner ear malformations [27, 28, 34]. CT with thin slice, multi-planar reconstruction of the temporal bone is required to evaluate inner ear malformations. CT and MR imaging can help distinguish subtypes and the severity of inner ear malformations. A CSF leak through the oval window can be observed in the region of the stapes footplate. Fluid protruding through the oval window on CT and MR imaging strongly suggests the presence of a fistula through the oval window (Fig. 5) [32]. Fluid accumulation in the middle ear and mastoid cells is also useful as an indirect finding linked to a CSF leak. 


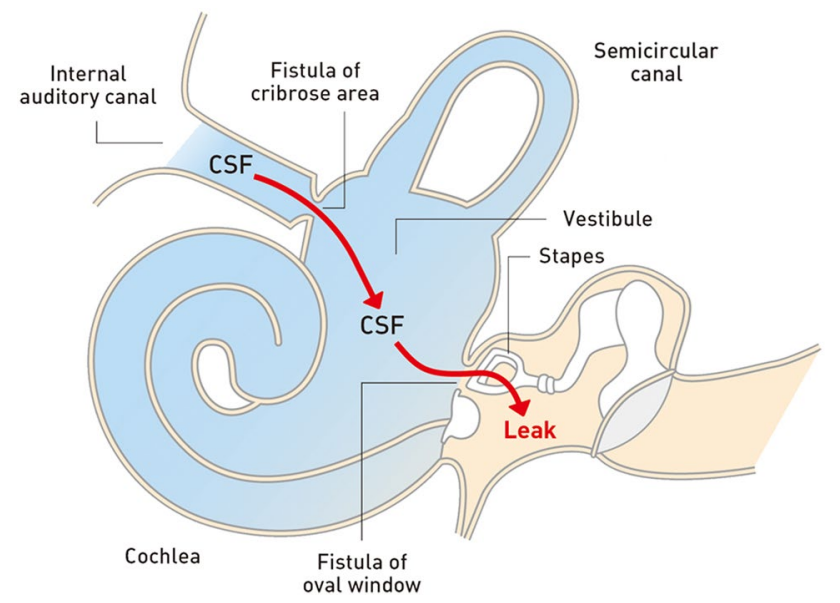

Fig. 4 Illustration of pathways of the internal auditory canal to external auditory canal fistulas. Bacterial meningitis results from the two fistulous connections: (1) between the internal auditory canal and the inner ear and (2) between the inner ear and middle ear. It is likely that a fistula of the cribriform area is a site of cerebrospinal fluid (CSF) leak, in the medial side of the inner ear in patients with an inner ear malformation. CSF leak to the middle ear from the inner ear can occur at the oval window due to the fistula in the region of the stapes footplate

Radionuclide cisternography is able to reveal the CSF leak as reflected in the accumulation of the radiotracer in the inner and middle ears. Single-photon emission computed tomography (SPECT)/CT fusion imaging in radionuclide cisternography is a useful technique for more accurate localization of CSF leak sites than planar images (Fig. 5) [35].

\section{Congenital skull base cephalocele}

\section{Clinical features}

Congenital skull base cephalocele is a herniation of intracranial contents through a skull base defect with an incidence of about 1:40,000 [36]. Congenital skull base cephaloceles might remain unrecognized at birth since the herniated content exists within the nasal or paranasal cavity and cannot be observed on physical examination. Skull base cephalocele can cause airway obstruction in the nose, nasopharynx, or oropharynx [36-38].

Congenital skull base cephaloceles can be classified into three different types according to the location: (1) transethmoidal cephalocele, (2) transsphenoidal cephalocele, and (3) sphenoorbital cephalocele [10, 37] (Fig. 6a). The pituitary gland, optic nerve, and hypothalamus commonly show deformities and herniation through the skull base defect in patients with transsphenoidal cephalocele, and visual disturbance and pituitary hypothalamic dysfunction can also be observed [36-38]. Transsphenoidal cephalocele is also associated with other congenital malformations, including holoprosencephaly, corpus callosum agenesis, and midfacial anomalies such as a cleft lip [37, 38].
Recurrent BM associated with a CSF leak from a skull base osseodural defect can occur in either type of congenital skull base cephalocele. S. pneumoniae is the most common causative organism of BM in patients with a congenital skull base cephalocele. A fiberoptic endoscopy is useful to observe a CSF leak and a herniated cephalocele in the nasal cavity.

\section{Management}

Surgical repair should be performed to prevent the recurrence of BM. The safety and efficacy of endoscopic endonasal approaches have been reported in recent years [39].

\section{Radiological assessment}

CT demonstrates the congenital osseous defect, continuous with the herniated contents, entering into the adjacent paranasal sinus or nasal cavity $[16,36]$. MR imaging would be useful to discriminate among the components of the herniated sac (i.e., CSF, brain tissue, or dysplastic gliotic tissue) (Fig. 6c). Scrutinizing CSF continuity between the herniated contents and subarachnoid space may be helpful in distinguishing skull base cephaloceles from intra-nasal tumors. MR imaging is also useful to visualize morphological abnormalities in adjacent structures, including the optic nerve, pituitary gland, and vascular structures $[16,36]$.

\section{Infection spread from the adjacent tissue to the CSF space with a structural defect: acquired structural defect}

\section{Skull base trauma}

\section{Clinical features}

CSF leaks occur in approximately $2 \%$ of head injuries and in about $10-30 \%$ of skull base fractures $[40,41]$. A CSF leak from a skull base trauma most commonly involves the anterior cranial fossa, resulting from fractures of the frontal sinus or cribriform plates of the ethmoid bones [15, 40]. In $80 \%$ of post-trauma patients, a CSF leak spontaneously resolves within $48 \mathrm{~h}$ after the occurrence of the skull base fracture. In patients with a persistent CSF leak after head trauma, the leak site usually becomes apparent within the first month, but some may remain unrecognized until several years after the trauma [7, 40-42]. BM occurs in 7-30\% of patients with a persistent CSF leak after a head trauma [40]. The causative organisms of BM in patients with a skull base fracture are $S$. pneumoniae and $H$. influenzae. Skull base trauma is the most common cause of recurrent BM associated with anatomical problems [7]. 

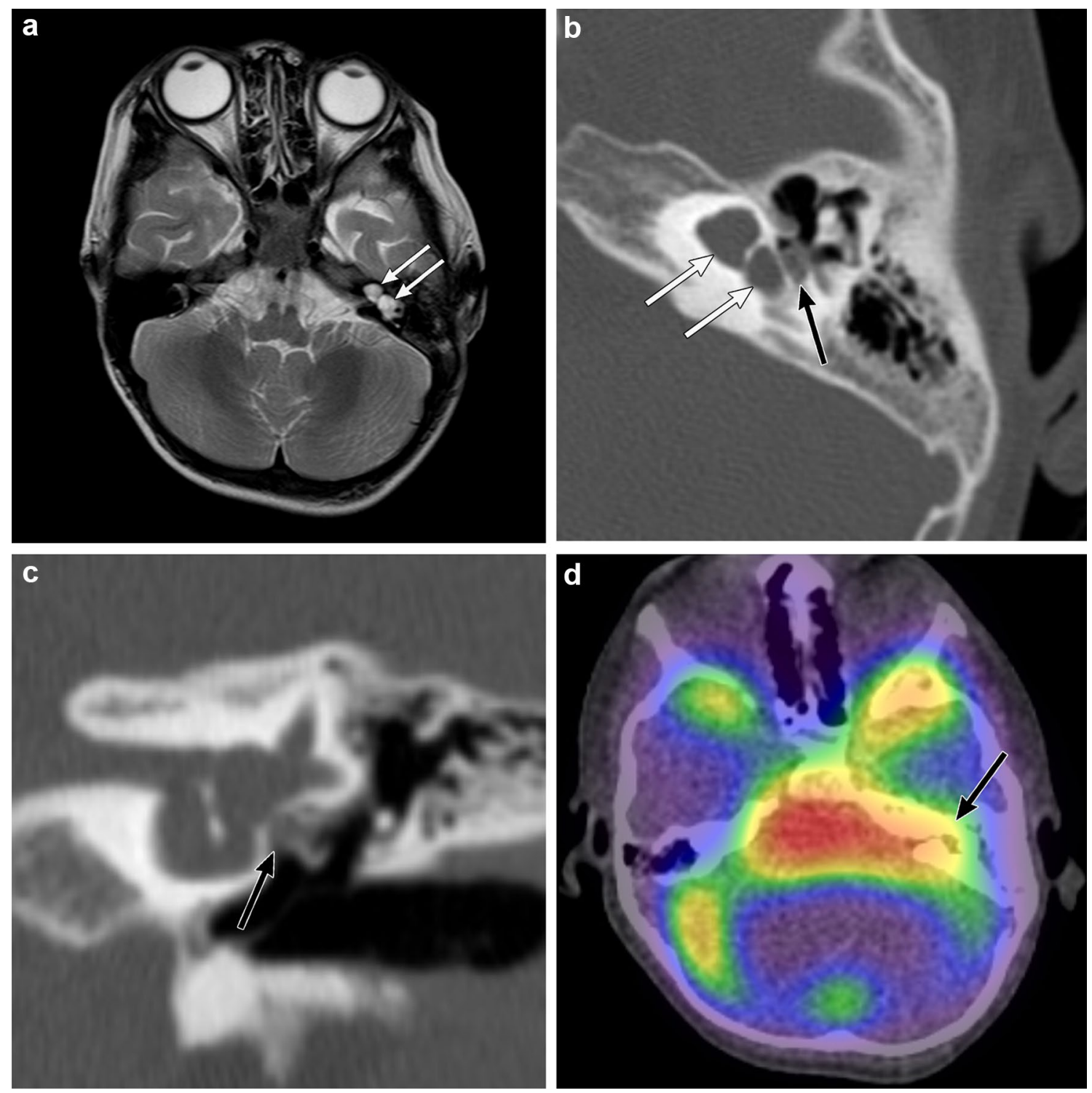

Fig. 5 Left inner ear malformation (incomplete partition type I) in a 5 -year-old boy with recurrent bacterial meningitis. The patient has left sensorineural hearing loss. a T2-weighted magnetic resonance image shows that the enlarged cochlea and vestibule in the left temporal bone suggest an inner ear malformation (white arrows). b Axial computed tomography (CT) of the temporal bone shows that the left cochlea has a cystic appearance and the vestibule is enlarged and cystic (white arrows). The cochlea and vestibule are separated, suggestive of incomplete partition type I. Fluid accumulation is observed in the lateral side of the left oval window, highly suggestive of a cer-

A detailed history of recent and remote traumatic events is essential to form a diagnosis. Rhinorrhea and otorrhea are common clinical symptoms in patients with a CSF leak. It should be noted that CSF rhinorrhea sometimes remains unrecognized [7]. Further investigations, including $\beta 2$-transferrin testing, fiberoptic endoscopy, and otoscopy, are required if either CSF rhinorrhea or otorrhea is suspected [7]. ebrospinal fluid (CSF) leak (black arrow). c Coronal CT of the temporal bone shows fluid accumulation protruding through the left oval window (black arrow), suggestive of a CSF leak through a fistula in the left oval window associated with inner ear malformations. d Radionuclide cisternography with a Single-photon emission CT/CT fusion image shows increased radiotracer accumulation in the left temporal bone (black arrow), and a CSF leak into the left middle ear is confirmed. Leak of CSF from a partial defect of the stapes footplate is confirmed during the surgical repair

\section{Management}

In the acute post-traumatic phase, most CSF leaks resolve with conservative treatments such as bed rest and head elevation [16]. Patients with persistent CSF leaks due to skull base fractures require surgical repair since these patients are at a higher risk of recurrent BM [16, 40, 41]. Other effective treatments include CSF tap and lumbar drain 

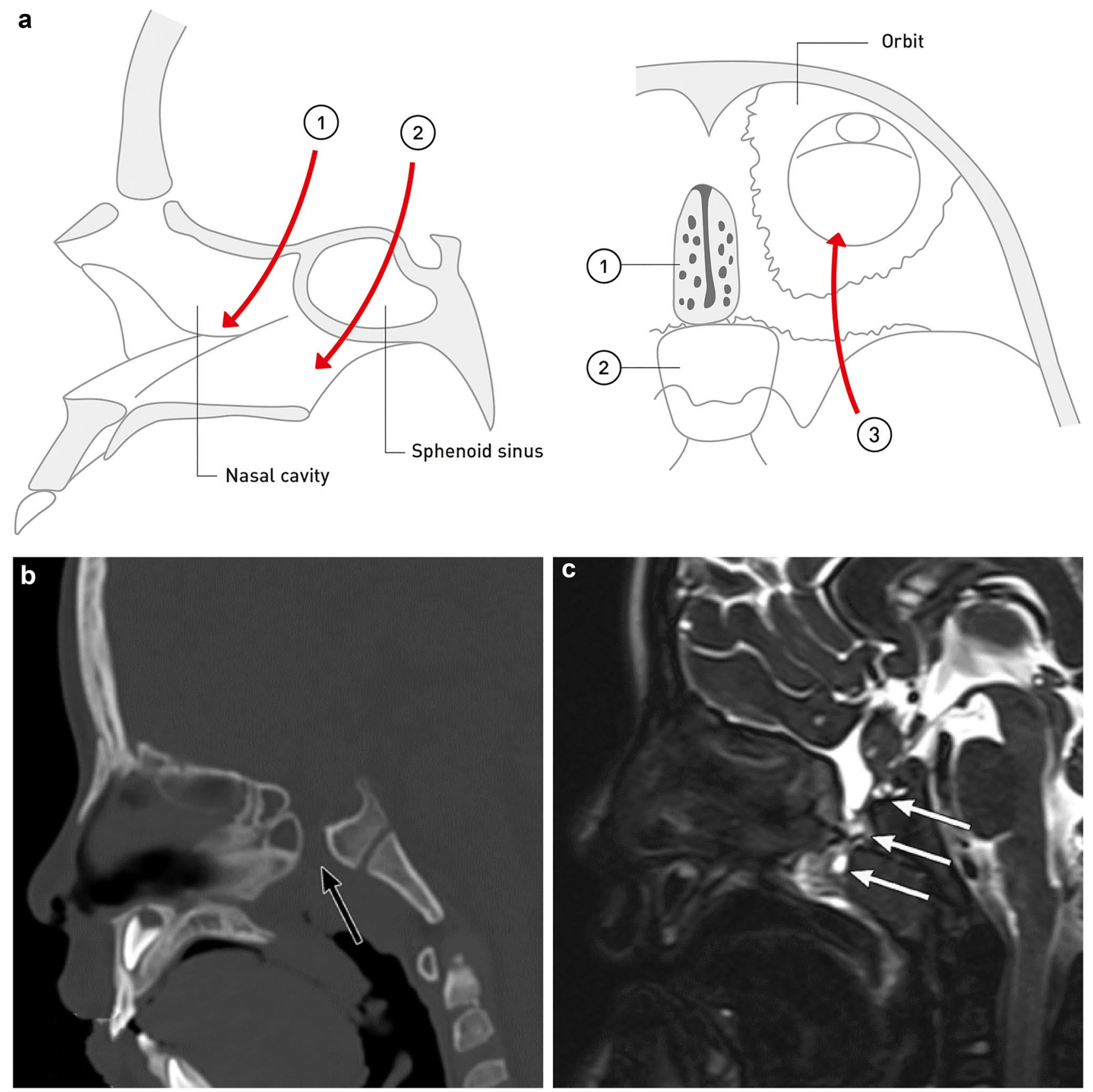

Fig. 6 Congenital skull base cephalocele. a Classification of congenital skull base cephalocele. Skull base cephaloceles are classified into (i) transethmoidal, (ii) transsphenoidal, and (iii) spheno-orbital. The arrows indicate the pathway by which intracranial contents protrude into the extracranial space through a skull base defect. b Congenital skull base cephalocele (transsphenoidal cephalocele) in a 5-year-old boy with bacterial meningitis and growth hormone deficiency. Sagittal head computed tomography shows a partial defect of the sphe-

placement, which could reduce intracranial pressure and facilitate healing. Appropriate vaccinations are required especially in patients who are not indicated to receive surgical repair [7, 43].

noid bone (black arrow). c Sagittal T2-weighted magnetic resonance image shows herniated contents extended into the nasopharynx through the defect of the sphenoid bone (transsphenoidal cephalocele). Herniated content shows heterogenous intensity, with fluid components showing high intensity, and herniated brain parenchyma and dysplastic gliotic tissue showing iso intensity (white arrows). The pituitary gland has a deformity and is herniating into the sphenoid bone defect

\section{Radiological assessment}

CT imaging can reveal skull base fractures causing CSF leaks. Identifying the anatomic location of the CSF leak is 
essential for surgical repair. Skull base fractures responsible for the CSF leak are sometimes very small and should be carefully evaluated with thin slice CT with multiplanar reconstruction [15-17]. Coronal CT images are required to assess fractures in the ethmoid roof and planum sphenoidale that are almost never apparent on axial CT images (Fig. 7).

MR imaging is useful for detecting CSF leaks and is indicated to discriminate meningoencephalocele, which contains brain parenchyma and meninges in the herniated content, from meningocele, which only contains meninges in the herniated content [15, 16, 44-46]. MR cisternography is a good indication for the localization of the CSF leak site in patients with multiple bone defects identified on CT scans [15]. Fluid accumulation in the middle ear, mastoid air cells, and paranasal sinuses can be an indirect sign of a CSF leak (Fig. 8).

Radionuclide cisternography is used to confirm a CSF leak if the CT and MR images cannot identify the CSF leak site. Radionuclide cisternography is limited to detecting CSF leaks that are active at the time of the study. Delayed image acquisition, up to 24-72 $\mathrm{h}$ after the administration of the radiotracer, could be beneficial for detecting intermittent CSF leaks $[15,16]$.

\section{Gorham-Stout disease}

\section{Clinical features}

Gorham-Stout disease, also known as massive osteolysis or vanishing bone disease, is a rare disorder characterized by progressive osteolysis. Pathologically, the disease is characterized by the proliferation and dilation of lymphatic vessels [47, 48]. Gorham-Stout disease can affect any part of the skeleton, but is more common in the ribs, cranium, pelvis, clavicle, and scapula. Pathologic fractures and skeletal pain are common symptoms [48]. Patients with craniofacial involvement of Gorham-Stout disease are at risk of CSF leaks, and some patients with temporal bone involvement suffer from BM due to CSF leaks [49-52]. BM may sometimes lead to a diagnosis of Gorham-Stout disease [51, 52].

\section{Management}

Several medications, including bisphosphonates, bevacizumab, and interferon-alpha $2 b$, have been used to treat patients with Gorham-Stout disease. A recent clinical trial is testing the efficacy of sirolimus [53]. Bone loss with functional impairment requires surgical resection and reconstruction [54]. Surgical repair of the skull base has been reported to be effective in terminating CSF leaks [50].

\section{Radiological assessment}

Gorham-Stout disease is characterized by cortical resorption and progressive, often extensive, osteolysis on radiographs and CT scans (Fig. 9). Gorham-Stout disease begins with lucencies in the intramedullary or subcortical regions, sparing the cortex [48]. Therefore, early bony lesions in

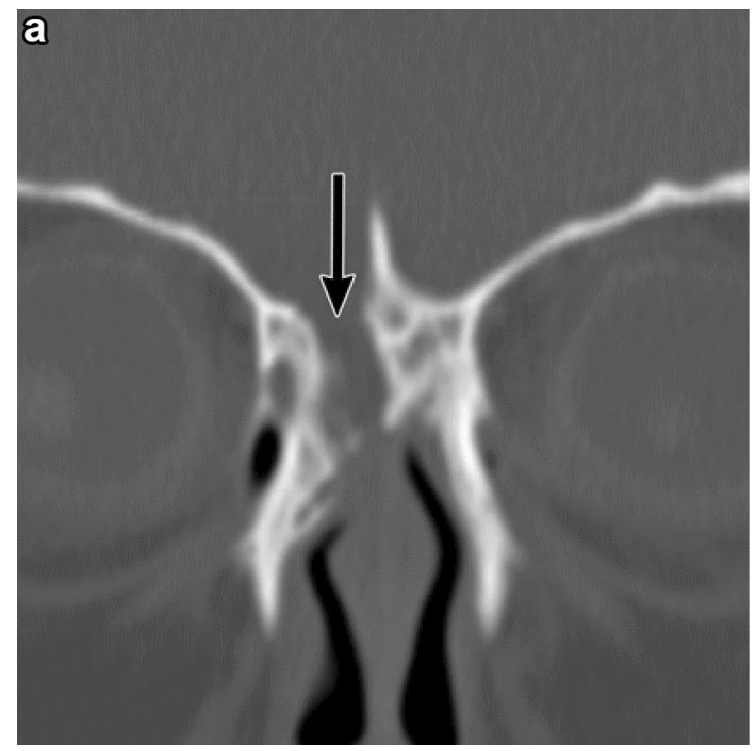

Fig. 7 Multiple skull base fractures in a 3-year-old boy with recurrent bacterial meningitis. The patient had a head injury in a traffic accident 2 years prior to presentation. a Coronal computed tomography shows that the cerebrospinal fluid space communicates with the ethmoid antrum through a partial defect of the cribriform plate

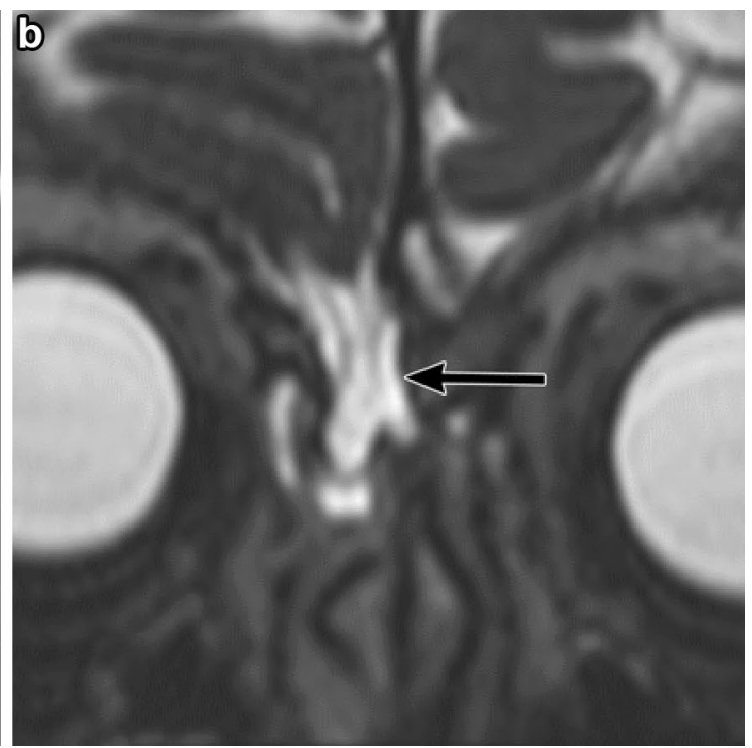

(black arrow). b Magnetic resonance (MR) cisternography (coronal T2-weighted MR image) shows the meningocele (black arrow) protruding through a defect of the cribriform plate. Although not shown here, there were also fractures in the left temporal bone 


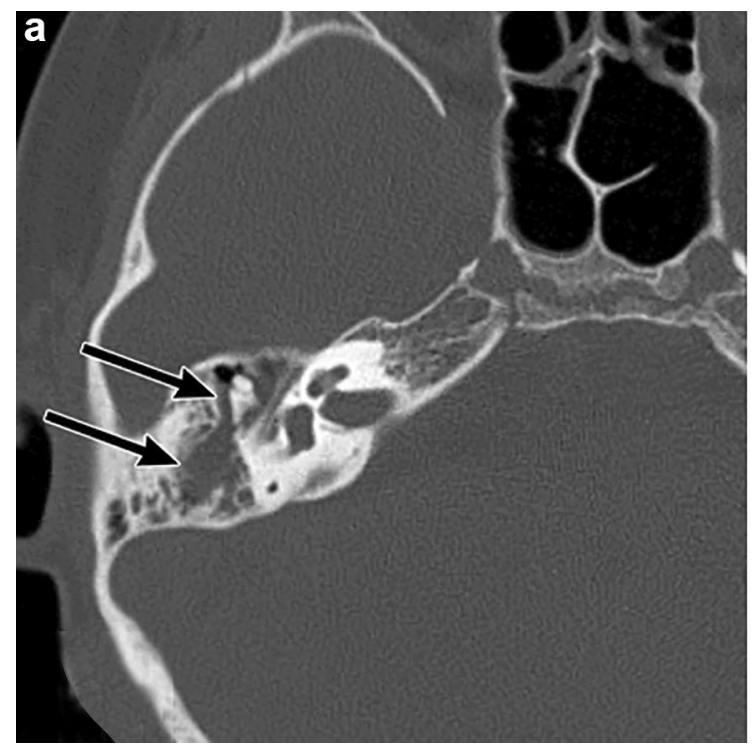

Fig. 8 Cerebrospinal fluid (CSF) leak in the right middle ear in a 10 -year-old boy who was diagnosed with bacterial meningitis five times. The patient had a head injury 8 years prior to presentation. a Axial temporal bone computed tomography shows fluid collection in the middle ear and mastoid air cells, suggestive of a CSF leak (black arrows). It is probably caused by remote head trauma, but fractures

Gorham-Stout disease are difficult to identify. CSF leaks should be suspected in Gorham-Stout disease with osteolysis of the skull base, especially the temporal bone, and fluid accumulation in the middle ear, the mastoid air cells, or fascial spaces.

MR imaging is useful to assess osteolytic lesions as well as CSF leaks. Bony involvements in Gorham-Stout disease show up as hyperintensities on T2-weighted images, similar to CSF, reflecting the lymphatic nature of this disorder (Fig. 9) [55]. Therefore, it may be difficult to identify CSF leaks in patients with Gorham-Stout disease. Radionuclide cisternography is useful to confirm CSF leaks in Gorham-Stout disease, as it is able to distinguish CSF leaks from a lymphatic anomaly (Fig. 9) [50].

\section{Infection spread from the adjacent tissue to the CSF space without a structural defect: parameningeal infections}

\section{Sinusitis}

\section{Clinical features}

Sinusitis is defined as an inflammation involving the paranasal sinuses mucosa. Common pathogens involved in

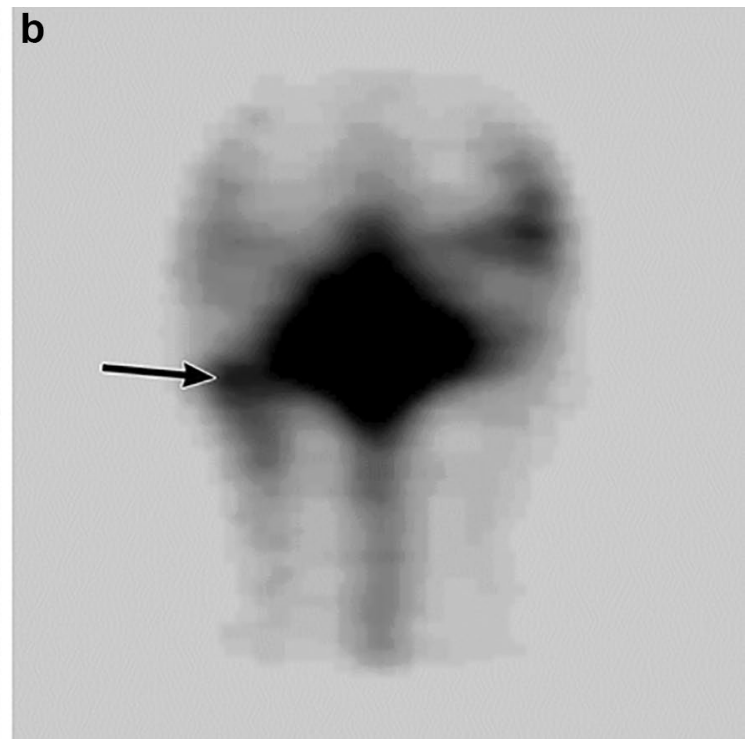

cannot be identified. b Radionuclide cisternography shows radionuclide accumulation in the right mastoid cells and the right middle ear, and a CSF leak was confirmed (black arrow). A lumbar-peritoneal shunt was performed to prevent the CSF leak. Surgical repair was not performed since the exact leak site remained unclear

bacterial sinusitis are Streptococcus pneumoniae, Haemophilus influenzae, and Moraxella catarrhalis [56]. Bacterial sinusitis is associated with not only BM but also other intracranial complications, including brain abscesses, epidural empyema, and dural sinus thrombosis. Intracranial infections associated with sinusitis have been reported in 3\% of hospitalized pediatric patients [57]. The frontal sinuses are most commonly associated with sinogenic intracranial infections [58]. The infection usually occurs via the progression of the septic thrombi through the cranial valveless diploic veins that penetrate the dura or, less commonly, through the direct intracranial extension of osteomyelitis [58-60].

Patients with sinusitis usually present with a purulent nasal discharge, cough, fever, headache, and nasal congestion. These symptoms sometimes remain unrecognized in children until their sinusitis worsens [61]. Therefore, initial radiological imaging for BM should be evaluated carefully to look for the presence of incidental sinusitis.

\section{Management}

Antimicrobial therapy is of primary importance in the management of intracranial complications. Surgical drainage of the paranasal cavity is sometimes required [59, 62]. Neurosurgical intervention to drain the intracranial abscess is required if it is associated with sinusitis. 

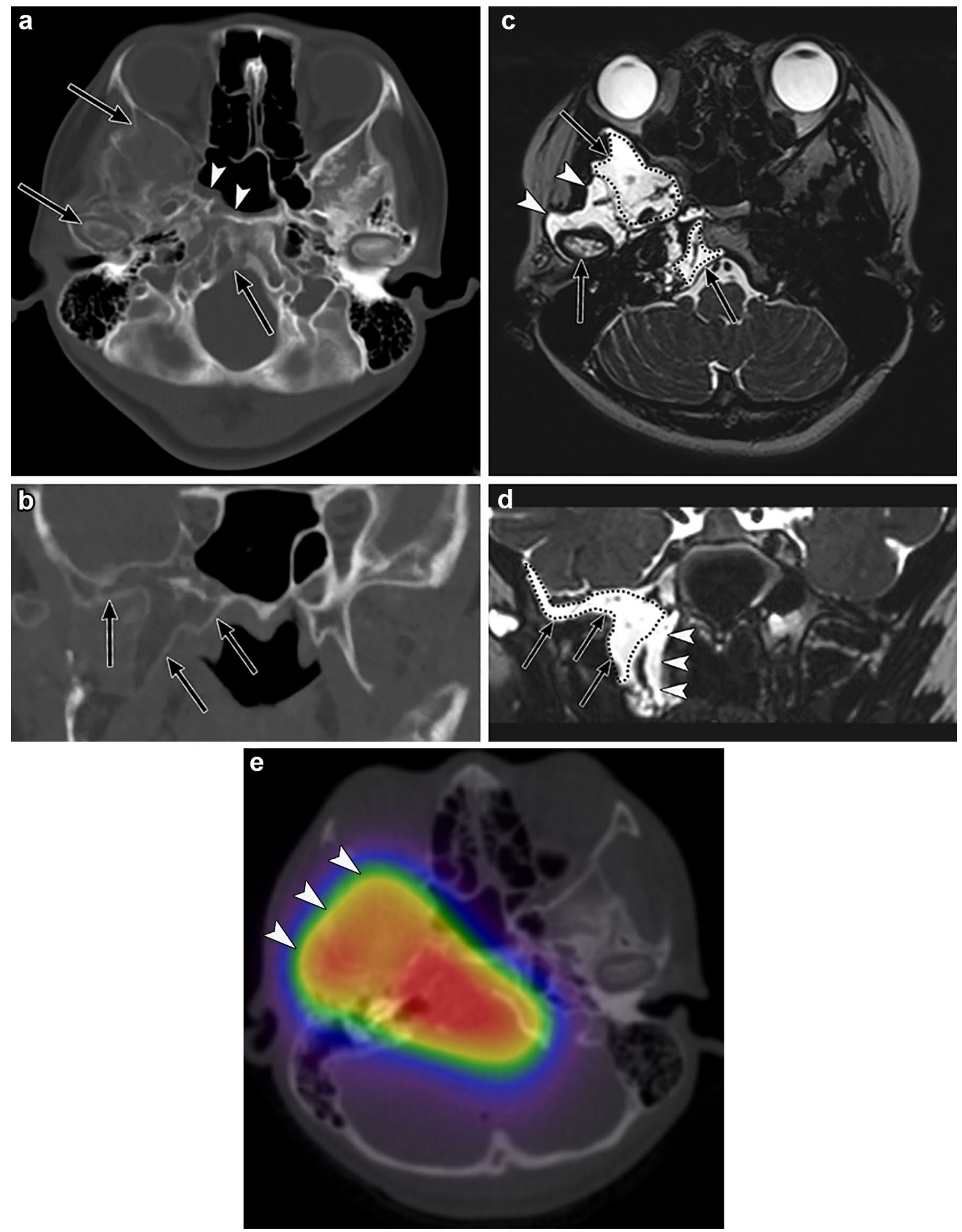

Fig. 9 Gorham-Stout disease in a 12-year-old girl with recurrent bacterial meningitis. The chief complaint was right neck pain and trismus. a, b Axial and coronal head computed tomography (CT) (bone window) show infiltrative osteolytic changes and expansion of the bone in the right skull base bone. The sphenoid bone and the right mandibular condyle are involved (black arrows). Fluid accumulation is observed in the sphenoid sinus (arrowheads). c, $\mathbf{d}$ Axial and coronal head magnetic resonance images (T2-weighted images) show that the right skull base is extensively involved and appears hyperintense (black arrows). Fluid accumulation is observed in the parapharyngeal space, suggestive of a cerebrospinal fluid (CSF) leak (arrowheads). Note that it is difficult to distinguish involved bones from a CSF leak because both show similar high intensities on T2-weighted images. $\mathbf{e}$ Single-photon emission CT/CT fusion imaging in radionuclide cisternography shows radionuclide accumulation in the right cervical fascial space, and a CSF leak is confirmed (arrowheads) 


\section{Radiological assessment}

$\mathrm{CT}$ and MR imaging findings of sinusitis include mucosal thickening, fluid accumulation, and mucosal enhancement. These findings are non-specific and do not necessarily reflect the severity of the symptoms. Therefore, imaging for acute, uncomplicated sinusitis is not usually recommended [14, 58, 63]. Where intracranial complications associated with sinusitis are suspected, CT with contrast enhancement and/or MRI with or without contrast enhancement, including the paranasal sinuses and cranium, is recommended. Contrast-enhanced MR imaging is superior to contrast-enhanced CT imaging in detecting meningitis and other intracranial complications [58]. Diffusion-weighted imaging can reveal suppurative material as it typically shows restricted diffusion (Fig. 10) [58]. In unilateral sinusitis, underlying odontogenic causes or the presence of foreign bodies in the paranasal cavity should also be evaluated (Fig. 10).

\section{Otitis media and mastoiditis}

\section{Clinical features}

Acute otitis media, an inflammation of the middle ear, is the most common infection during the first 5 years of life [13]. Acute mastoiditis, a serious complication of acute otitis media, also mainly occurs in young children. S. pneumoniae and group A beta-hemolytic streptococcus are the most common pathogens for BM in patients with acute otitis media. Infections spreading to the bony structure cause osteomyelitis. Infections spreading beyond the temporal bone cause intracranial complications, including BM, intracranial abscesses, and vascular thrombosis. Epidural abscesses and sinus thrombosis are common complications associated with mastoiditis in children [13]. Symptoms of otitis media and mastoiditis include otalgia, ear discharge, and retroauricular inflammation [64]. In coalescent mastoiditis, the demineralization of bone septa and osteonecrosis of the thinner mastoid walls result in the creation of large purulent cavities [13].

\section{Management}

A mastoidectomy should be performed in patients with intracranial complications [64]. Coalescent mastoiditis usually requires surgical drainage. Therefore, early detection of coalescent mastoiditis by radiological imaging is crucially important [14].

\section{Radiological assessment}

$\mathrm{CT}$ and MR images show fluid accumulation in the middle ear and the mastoid air cells. CT imaging shows erosion of the mastoid septa or mastoid wall in patients with coalescent mastoiditis (Fig. 11) [13, 14]. Patients with coalescent mastoiditis are more likely to have intracranial

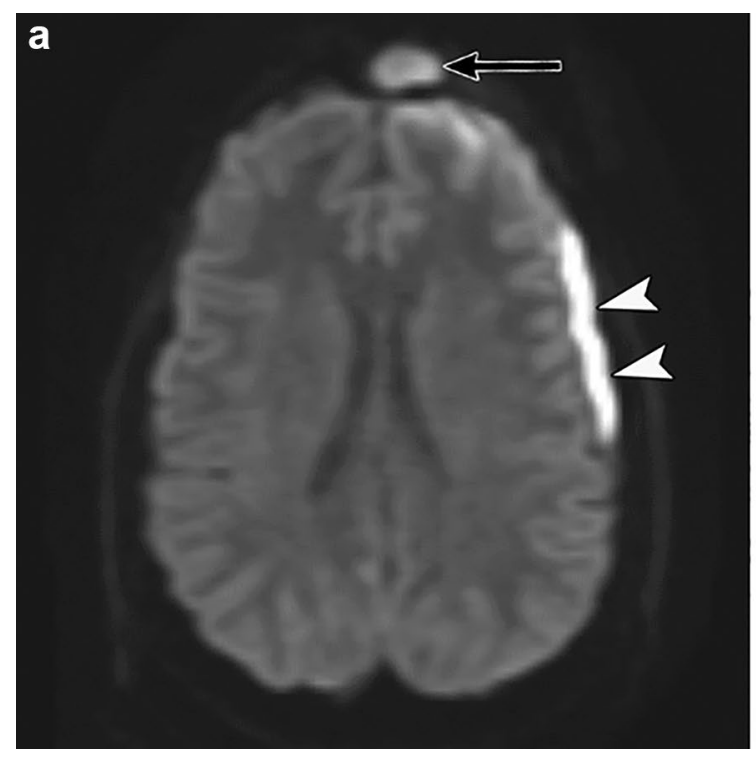

Fig. 10 Odontogenic sinusitis in a 12-year-old girl with bacterial meningitis. a Diffusion-weighted image shows subdural fluid accumulation with diffusion restriction, suggestive of subdural empyema (arrowheads). Restricted diffusion is also observed in the frontal sinus (black arrow). b Coronal computed tomography (bone window) shows the left maxillary sinus with massive fluid accumula-

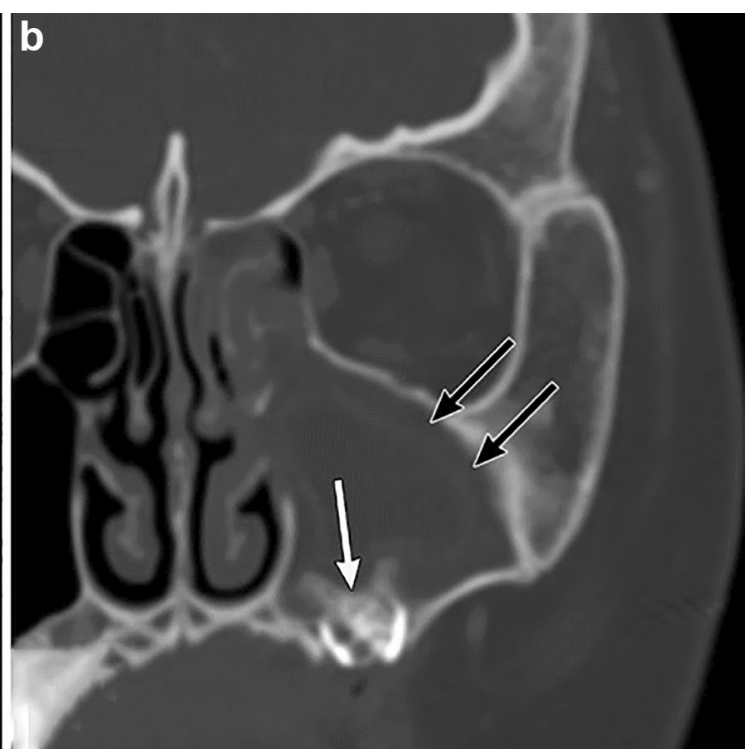

tion and mucosal thickening (black arrows). Impacted decaying teeth are observed in the left maxillary sinus (white arrow), confirming the diagnosis of odontogenic sinusitis. Surgical drainage for subdural empyema and endoscopic sinus surgery were performed. The impacted teeth were extracted 
infections and venous thrombosis than those with mastoiditis without bone destruction [14]. The absence of flow void in spin-echo $\mathrm{T} 2$-weighted images points to the presence of dural venous thrombosis (Fig. 11). Dural venous thrombus can be observed as a low-intensity intravascular structure on T2-weighted gradient-echo MR images. Contrast-enhanced CT and contrast-enhanced
MR are generally required to make a definitive diagnosis of dural venous thrombosis. Contrast-enhanced MR venography depicts dural venous thrombosis better than non-contrast time-of-flight MR venography since the image quality is affected by the turbulent flow in the vessels $[13,65]$.
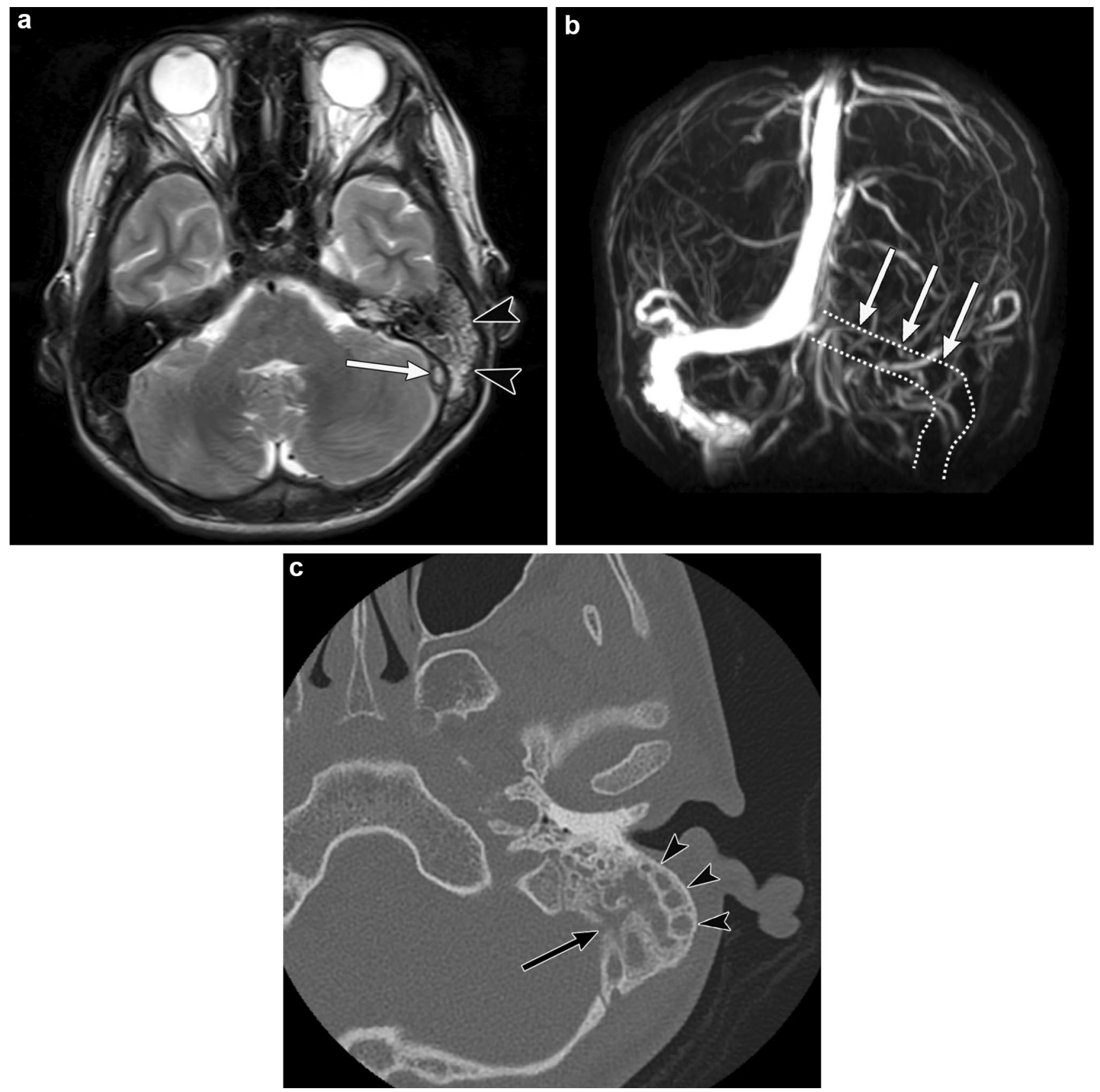

Fig. 11 Mastoiditis in a 13-year-old boy with bacterial meningitis. a Axial T2-weighted magnetic resonance (MR) image shows fluid collection in the left mastoid bone (arrowheads). The left sigmoid sinus shows the absence of a flow void, suggestive of sinus thrombosis (white arrow). b Maximum-intensity projection of a contrast- enhanced MR venogram shows a complete thrombosis of the left sigmoid sinus to the left transverse sinus (white arrows). c Axial computed tomography (bone window) shows fluid accumulation in the left mastoid air cells (arrowheads). The medial mastoid wall shows lytic changes (black arrow) 


\section{Immunodeficiency}

\section{Hyposplenism}

\section{Clinical features}

Hyposplenism is defined as the impairment of splenic function, and is associated with several disorders such as sicklecell anemia, bone marrow transplantation, graft-versus-host disease, and splenic morphological abnormalities including polysplenia and asplenia [66]. The spleen plays an important role in immunological functions. Antibody production is important to remove encapsulated bacteria, including $S$. pneumoniae, H. influenzae, and Neisseria meningitides [66]. Patients with hyposplenism are at an increased risk of severe infections with encapsulated bacteria, including recurrent BM [7, 66-69]. Both asplenia and polysplenia can cause hyposplenism, leading to severe bacterial infections, including meningitis [70, 71]. A history of previous abdominal trauma or surgery should raise the suspicion of hyposplenism [7]. The detection of Howell-Jolly bodies, erythrocytes with nuclear remnants, is a useful technique for screening for hyposplenism [66].

\section{Management}

Appropriate vaccinations and antibiotic prophylaxis are required for patients with splenic dysfunction to prevent severe infections, including BM [70].

\section{Radiological assessment}

Abdominal US or CT imaging can allow for the visualization of the morphology and the size of spleen (Fig. 12). In patients with congenital asplenia or polysplenia, an underlying heterotaxy syndrome and associated complex congenital anomalies should also be assessed. The malformations including complex congenital heart disease and midgut malrotation that can influence prognosis must be carefully evaluated on imaging $[71,72]$.

\section{Conclusion}

One of the roles of the radiologist in managing $\mathrm{BM}$ is to diagnose predisposing conditions. Predisposing conditions for recurrent $\mathrm{BM}$ can be broadly classified into two categories: infection spread from the adjacent tissue to the CSF space and immunodeficiency. Diseases in the former category are further divided according to whether there is a structural defect between the CSF space and

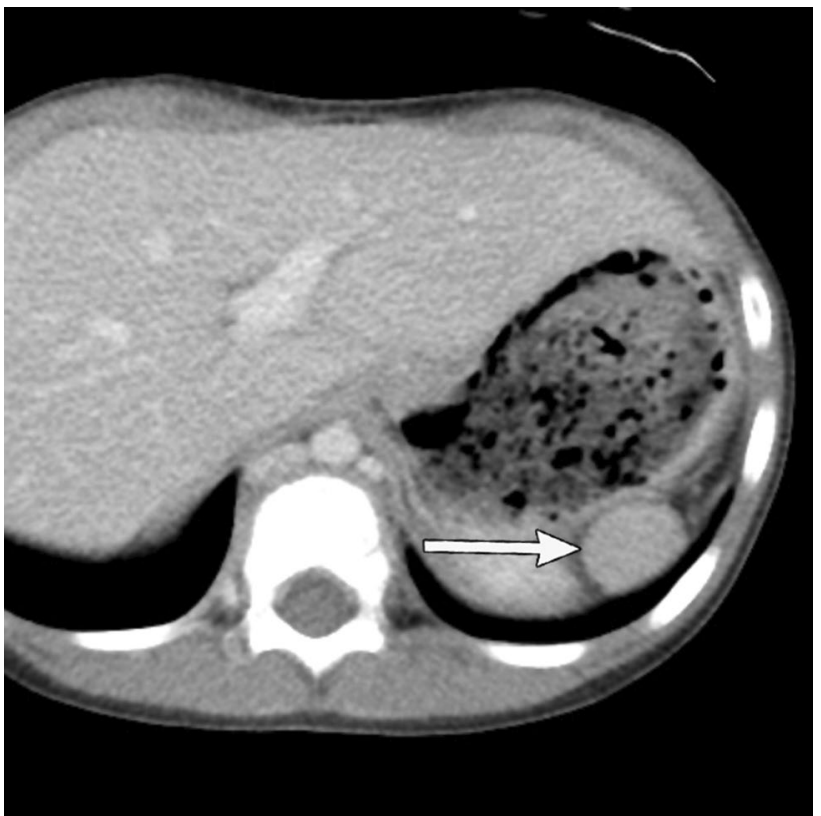

Fig. 12 Hyposplenism in a 1-year-old boy with bacterial meningitis. Howell-Jolly bodies and target cells were confirmed. Contrastenhanced computed tomography imaging confirmed the presence of a small singular spleen without a parent spleen (white arrow)

the adjacent tissue. Knowledge of the clinical features and imaging findings linked to these predisposing conditions and an appropriate radiological approach may enable early diagnosis, treatment, and prevention of recurrent BM.

Acknowledgements We are grateful to Hirofumi Kuno, Tsukasa Saida, Toshitaka Ishiguro, Masafumi Sakai, Hiroshi Nagamatsu, and Rumi Imai for their valuable advice. We would like to thank Haruka Asano for figure illustrations.

Author contributions SM and OM had the idea for the article. SM, OM, HT, YT, TH, MM, and SN performed the literature search and data analysis. All authors critically revised the manuscript, commented on drafts of the manuscript, and approved the final manuscript.

Funding This article was supported by a grant from the National Center for Child Health and Development, Japan, 2019B-19.

Availability of data and material Not applicable.

Code availability Not applicable.

\section{Declarations}

Conflict of interest The authors declare that they have no conflict of interest.

Ethical statement This article does not contain any studies with human participants or animals performed by any of the authors. 
Open Access This article is licensed under a Creative Commons Attribution 4.0 International License, which permits use, sharing, adaptation, distribution and reproduction in any medium or format, as long as you give appropriate credit to the original author(s) and the source, provide a link to the Creative Commons licence, and indicate if changes were made. The images or other third party material in this article are included in the article's Creative Commons licence, unless indicated otherwise in a credit line to the material. If material is not included in the article's Creative Commons licence and your intended use is not permitted by statutory regulation or exceeds the permitted use, you will need to obtain permission directly from the copyright holder. To view a copy of this licence, visit http://creativecommons.org/licenses/by/4.0/.

\section{References}

1. Kim KS. Acute bacterial meningitis in infants and children. Lancet Infect Dis. 2010;10:32-42. https://doi.org/10.1016/S14733099(09)70306-8.

2. Drummond DS, de Jong AL, Giannoni C, Sulek M, Friedman EM. Recurrent meningitis in the pediatric patient - the otolaryngologist's role. Int J Pediatr Otorhinolaryngol. 1999;48:199-208. https://doi.org/10.1016/S0165-5876(99)00022-1.

3. Masri A, Alassaf A, Khuri-Bulos N, Zaq I, Hadidy A, Bakri FG. Recurrent meningitis in children: etiologies, outcome, and lessons to learn. Childs Nerv Syst. 2018;34:1541-7. https://doi.org/10. 1007/s00381-018-3815-9.

4. Agrawal S, Nadel S. Acute bacterial meningitis in infants and children: epidemiology and management. Paediatr Drugs. 2011;13:385-400. https://doi.org/10.2165/11593340-00000 0000-00000.

5. Thigpen MC, Whitney CG, Messonnier NE, Zell ER, Lynfield R, Hadler JL, et al. Bacterial meningitis in the United States, 19982007. N Engl J Med. 2011;364:2016-25. https://doi.org/10.1056/ NEJMoa1005384.

6. Shinjoh M, Iwata S, Yagihashi T, Sato Y, Akita H, Takahashi T, et al. Recent trends in pediatric bacterial meningitis in Japan-a country where Haemophilus influenzae type b and Streptococcus pneumoniae conjugated vaccines have just been introduced. $\mathrm{J}$ Infect Chemother. 2014;20:477-83. https://doi.org/10.1016/j.jiac. 2014.04.007.

7. Tebruegge M, Curtis N. Epidemiology, etiology, pathogenesis, and diagnosis of recurrent bacterial meningitis. Clin Microbiol Rev. 2008;21:519-37. https://doi.org/10.1128/CMR.00009-08.

8. Darmaun L, Levy C, Lagree M, Béchet S, Varon E, Dessein R, et al. Recurrent pneumococcal meningitis in children: a multicenter case-control study. Pediatr Infect Dis J. 2019;38:881-6. https://doi.org/10.1097/INF.0000000000002358.

9. Tunkel AR, Hartman BJ, Kaplan SL, Kaufman BA, Roos KL, Scheld WM, et al. Practice guidelines for the management of bacterial meningitis. Clin Infect Dis. 2004;39:1267-84. https://doi. org/10.1086/425368.

10. Osborn AG, Hedlund GL, Salzman KL. Osborn's brain: imaging, pathology, and anatomy: Amirsys Salt Lake City; 2013.

11. Barkovich AJ, Edwards M, Cogen PH. MR evaluation of spinal dermal sinus tracts in children. AJNR Am J Neuroradiol. 1991;12:123-9.

12. Unsinn KM, Geley T, Freund MC, Gassner I. US of the spinal cord in newborns: spectrum of normal findings, variants, congenital anomalies, and acquired diseases. Radiographics. 2000;20:92338. https://doi.org/10.1148/radiographics.20.4.g00j106923.

13. Vazquez E, Castellote A, Piqueras J, Mauleon S, Creixell S, Pumarola F, et al. Imaging of complications of acute mastoiditis in children. Radiographics. 2003;23:359-72. https://doi.org/10. 1148/rg.232025076.

14. Ludwig BJ, Foster BR, Saito N, Nadgir RN, Castro-Aragon I, Sakai O. Diagnostic imaging in nontraumatic pediatric head and neck emergencies. Radiographics. 2010;30:781-99. https://doi. org/10.1148/rg.303095156.

15. Lloyd KM, DelGaudio JM, Hudgins PA. Imaging of skull base cerebrospinal fluid leaks in adults. Radiology. 2008;248:725-36. https://doi.org/10.1148/radiol.2483070362.

16. Hiremath SB, Gautam AA, Sasindran V, Therakathu J, Benjamin G. Cerebrospinal fluid rhinorrhea and otorrhea: a multimodality imaging approach. Diagn Interv Imaging. 2019;100:3-15. https://doi.org/10.1016/j.diii.2018.05.003.

17. La Fata V, McLean N, Wise SK, DelGaudio JM, Hudgins PA. CSF leaks: correlation of high-resolution CT and multiplanar reformations with intraoperative endoscopic findings. AJNR Am J Neuroradiol. 2008;29:536-41. https://doi.org/10.3174/ ajnr.A0885.

18. Ackerman LL, Menezes AH. Spinal congenital dermal sinuses: a 30-year experience. Pediatrics. 2003;112:641-7. https://doi.org/ 10.1542/peds.112.3.641.

19. Radmanesh F, Nejat F, El Khashab M. Dermal sinus tract of the spine. Childs Nerv Syst. 2010;26:349-57. https://doi.org/10.1007/ s00381-009-0962-z.

20. Singh I, Rohilla S, Kumar P, Sharma S. Spinal dorsal dermal sinus tract: an experience of 21 cases. Surg Neurol Int. 2015;6:S429-34. https://doi.org/10.4103/2152-7806.166752.

21. Schenk JP, Herweh C, Gunther P, Rohrschneider W, Zieger B, Troger J. Imaging of congenital anomalies and variations of the caudal spine and back in neonates and small infants. Eur J Radiol. 2006;58:3-14. https://doi.org/10.1016/j.ejrad.2005.12.004.

22. Korsvik HE, Keller MS. Sonography of occult dysraphism in neonates and infants with MR imaging correlation. Radiographics. 1992;12:297-306. https://doi.org/10.1148/radiographics.12.2. 1561418 (discussion 307-298).

23. Dev R, Husain M, Gupta A, Gupta RK. MR of multiple intraspinal abscesses associated with congenital dermal sinus. AJNR Am J Neuroradiol. 1997;18:742-3.

24. Lee SM, Cheon JE, Choi YH, Kim IO, Kim WS, Cho HH, Lee JY, Wang KC. Limited dorsal myeloschisis and congenital dermal sinus: comparison of clinical and MR imaging features. AJNR Am J Neuroradiol. 2017;38:176-82. https://doi.org/10.3174/ajnr. A4958.

25. Jackler RK, Luxford WM, House WF. Congenital malformations of the inner ear: a classification based on embryogenesis. Laryngoscope. 1987;97:2-14. https://doi.org/10.1002/lary.5540971301.

26. Kontorinis G, Goetz F, Giourgas A, Lenarz T, Lanfermann H, Giesemann AM. Radiological diagnosis of incomplete partition type I versus type II: significance for cochlear implantation. Eur Radiol. 2012;22:525-32. https://doi.org/10.1007/ s00330-011-2301-5.

27. Joshi VM, Navlekar SK, Kishore GR, Reddy KJ, Kumar EC. CT and MR imaging of the inner ear and brain in children with congenital sensorineural hearing loss. Radiographics. 2012;32:68398. https://doi.org/10.1148/rg.323115073.

28. Lowe LH, Vezina LG. Sensorineural hearing loss in children. Radiographics. 1997;17:1079-93. https://doi.org/10.1148/radio graphics.17.5.9308102.

29. Muzzi E, Battelino S, Gregori M, Pellegrin A, Orzan E. Lifethreatening unilateral hearing impairments. Review of the literature on the association between inner ear malformations and meningitis. Int J Pediatr Otorhinolaryngol. 2015;79:1969-74. https:// doi.org/10.1016/j.ijporl.2015.09.028.

30. Yilmaz Ciftdogan D, Bayram N, Ozdemir Y, Bayraktaroglu S, Vardar F. A case of Mondini dysplasia with recurrent Streptococcus 
pneumoniae meningitis. Eur J Pediatr. 2009;168:1533-5. https:// doi.org/10.1007/s00431-009-0954-8.

31. Sharawat IK, Kasinathan A, Peruri GP, Saini AG, Sankhyan N, Saxena AK, Singh P. Recurrent Streptococcus pneumoniae meningitis and Mondini dysplasia: association or causation? J Infect Public Health. 2019;12:101-3. https://doi.org/10.1016/j.jiph.2018. 04.002 .

32. Coley BD. Caffey's pediatric diagnostic imaging E-Book. New York: Elsevier Health Sciences; 2018.

33. Schuknecht HF. Mondini dysplasia; a clinical and pathological study. Ann Otol Rhinol Laryngol. 1980. https://doi.org/10.1177/ 00034894800890S101.

34. Young JY, Ryan ME, Young NM. Preoperative imaging of sensorineural hearing loss in pediatric candidates for cochlear implantation. Radiographics. 2014;34:E133-49. https://doi.org/ 10.1148/rg.345130083.

35. Novotny C, Potzi C, Asenbaum S, Peloschek P, Suess E, Hoffmann M. SPECT/CT fusion imaging in radionuclide cisternography for localization of liquor leakage sites. J Neuroimaging. 2009;19:227-34. https://doi.org/10.1111/j.1552-6569.2008. 00270.x.

36. Connor SE. Imaging of skull-base cephalocoeles and cerebrospinal fluid leaks. Clin Radiol. 2010;65:832-41. https://doi.org/10. 1016/j.crad.2010.05.002.

37. Yokota A, Matsukado Y, Fuwa I, Moroki K, Nagahiro S. Anterior basal encephalocele of the neonatal and infantile period. Neurosurgery. 1986;19:468-78. https://doi.org/10.1227/00006123198609000-00025.

38. Mylanus EA, Marres HA, Vlietman J, Kollée LA, Freihofer HP, Thijssen HO, et al. Transalar sphenoidal encephalocele and respiratory distress in a neonate: a case report. Pediatrics. 1999;103:E12. https://doi.org/10.1542/peds.103.1.e12.

39. Thompson HM, Schlosser RJ, McCarty Walsh E, Cho DY, Grayson JW, et al. Current management of congenital anterior cranial base encephaloceles. Int J Pediatr Otorhinolaryngol. 2020;131: 109868. https://doi.org/10.1016/j.ijporl.2020.109868.

40. Friedman JA, Ebersold MJ, Quast LM. Post-traumatic cerebrospinal fluid leakage. World J Surg. 2001;25:1062-6. https://doi.org/ 10.1007/s00268-001-0059-7.

41. Yilmazlar S, Arslan E, Kocaeli H, Dogan S, Aksoy K, Korfali E, et al. Cerebrospinal fluid leakage complicating skull base fractures: analysis of 81 cases. Neurosurg Rev. 2006;29:64-71. https:// doi.org/10.1007/s10143-005-0396-3.

42. Adepoju A, Adamo MA. Posttraumatic complications in pediatric skull fracture: dural sinus thrombosis, arterial dissection, and cerebrospinal fluid leakage. J Neurosurg Pediatr. 2017;20:598-603. https://doi.org/10.3171/2017.6.PEDS16702.

43. Ter Horst L, Brouwer MC, van der Ende A, van de Beek D. Community-acquired bacterial meningitis in adults with cerebrospinal fluid leakage. Clin Infect Dis. 2020;70:2256-61. https://doi.org/ 10.1093/cid/ciz649.

44. Bathla G, Moritani T. Imaging of cerebrospinal fluid leak. Semin Ultrasound CT MR. 2016;37:143-9. https://doi.org/10.1053/j.sult. 2015.12.002

45. Algin O, Hakyemez B, Gokalp G, Ozcan T, Korfali E, Parlak M. The contribution of 3D-CISS and contrast-enhanced MR cisternography in detecting cerebrospinal fluid leak in patients with rhinorrhoea. Br J Radiol. 2010;83:225-32. https://doi.org/10.1259/ bjr/56838652.

46. El Gammal T, Sobol W, Wadlington VR, Sillers MJ, Crews C, Fisher WS 3rd, et al. Cerebrospinal fluid fistula: detection with MR cisternography. AJNR Am J Neuroradiol. 1998;19:627-31.

47. Gorham LW, Wright AW, Shultz HH, Maxon FC Jr. Disappearing bones: a rare form of massive osteolysis; report of two cases, one with autopsy findings. Am J Med. 1954;17:674-82. https://doi. org/10.1016/0002-9343(54)90027-3.
48. Lala S, Mulliken JB, Alomari AI, Fishman SJ, Kozakewich HP, Chaudry G. Gorham-Stout disease and generalized lymphatic anomaly-clinical, radiologic, and histologic differentiation. Skelet Radiol. 2013;42:917-24. https://doi.org/10.1007/ s00256-012-1565-4.

49. Kato H, Ozeki M, Fukao T, Matsuo M. Craniofacial CT findings of Gorham-Stout disease and generalized lymphatic anomaly. Neuroradiology. 2016;58:801-6. https://doi.org/10.1007/ s00234-016-1691-0.

50. Morimoto N, Ogiwara H, Miyazaki O, Kitamuara M, Nishina S, Nakazawa A, et al. Gorham-Stout syndrome affecting the temporal bone with cerebrospinal fluid leakage. Int J Pediatr Otorhinolaryngol. 2013;77:1596-600. https://doi.org/10.1016/j.ijporl. 2013.06.004.

51. Hernandez-Marques C, Serrano Gonzalez A, Cordobes Ortega F, Alvarez-Coca J, Sirvent Cerda S, Carceller Lechón F, et al. Gorham-Stout disease and cerebrospinal fluid otorrhea. Pediatr Neurosurg. 2011;47:299-302. https://doi.org/10.1159/000336877.

52. Nazarian GK, Gebarski SS, Niparko JK. Cranial lymphangiomatosis causing CSF otorrhea and recurrent meningitis: CT features. J Comput Assist Tomogr. 1990;14:121-3. https://doi.org/10.1097/ 00004728-199001000-00023.

53. Dellinger MT, Garg N, Olsen BR. Viewpoints on vessels and vanishing bones in Gorham-Stout disease. Bone. 2014;63:47-52. https://doi.org/10.1016/j.bone.2014.02.011.

54. Hagendoorn J, Yock TI, Borel Rinkes IH, Padera TP, Ebb DH. Novel molecular pathways in Gorham disease: implications for treatment. Pediatr Blood Cancer. 2014;61:401-6. https://doi.org/ 10.1002/pbc.24832.

55. Kato H, Ozeki M, Fukao T, Matsuo M. MR imaging findings of vertebral involvement in Gorham-Stout disease, generalized lymphatic anomaly, and kaposiform lymphangiomatosis. Jpn J Radiol. 2017;35:606-12. https://doi.org/10.1007/s11604-017-0674-3.

56. Wald ER, Applegate KE, Bordley C, Darrow DH, Glode MP, Marcy SM, et al. Clinical practice guideline for the diagnosis and management of acute bacterial sinusitis in children aged 1-18 years. Pediatrics. 2013;132:e262-80. https://doi.org/10.1542/peds. 2013-1071.

57. Lerner DN, Choi SS, Zalzal GH, Johnson DL. Intracranial complications of sinusitis in childhood. Ann Otol Rhinol Laryngol. 1995;104:288-93. https://doi.org/10.1177/000348949510400406.

58. Expert Panel on Pediatric Imaging, Tekes A, Palasis S, Durand DJ, Pruthi S, Booth TN, et al. ACR Appropriateness Criteria((R)) Sinusitis-Child. J Am Coll Radiol. 2018;15:S403-12. https://doi. org/10.1016/j.jacr.2018.09.029.

59. Patel NA, Garber D, Hu S, Kamat A. Systematic review and case report: intracranial complications of pediatric sinusitis. Int J Pediatr Otorhinolaryngol. 2016;86:200-12. https://doi.org/10.1016/j. ijporl.2016.05.009.

60. Brook I. Microbiology and antimicrobial treatment of orbital and intracranial complications of sinusitis in children and their management. Int J Pediatr Otorhinolaryngol. 2009;73:1183-6. https:// doi.org/10.1016/j.ijporl.2009.01.020.

61. Giannoni C, Sulek M, Friedman EM. Intracranial complications of sinusitis: a pediatric series. Am J Rhinol. 1998;12:173-8. https:// doi.org/10.2500/105065898781390127.

62. Germiller JA, Monin DL, Sparano AM, Tom LW. Intracranial complications of sinusitis in children and adolescents and their outcomes. Arch Otolaryngol Head Neck Surg. 2006;132:969-76. https://doi.org/10.1001/archotol.132.9.969.

63. Kronemer KA, McAlister WH. Sinusitis and its imaging in the pediatric population. Pediatr Radiol. 1997;27:837-46. https://doi. org/10.1007/s002470050251.

64. Psarommatis IM, Voudouris C, Douros K, Giannakopoulos P, Bairamis T, et al. Algorithmic management of pediatric acute 
mastoiditis. Int J Pediatr Otorhinolaryngol. 2012;76:791-6. https://doi.org/10.1016/j.ijporl.2012.02.042.

65. Leach JL, Fortuna RB, Jones BV, Gaskill-Shipley MF. Imaging of cerebral venous thrombosis: current techniques, spectrum of findings, and diagnostic pitfalls. Radiographics. 2006;26(Suppl 1):S19-41. https://doi.org/10.1148/rg.26si055174.

66. Di Sabatino A, Carsetti R, Corazza GR. Post-splenectomy and hyposplenic states. Lancet. 2011;378:86-97. https://doi.org/10. 1016/S0140-6736(10)61493-6.

67. Gaschignard J, Levy C, Chrabieh M, Boisson B, Bost-Bru C, Dauger $\mathrm{S}$, et al. Invasive pneumococcal disease in children can reveal a primary immunodeficiency. Clin Infect Dis. 2014;59:24451. https://doi.org/10.1093/cid/ciu274.

68. Ballegaard VC, Schejbel L, Hoffmann S, Kantso B, Fischer CP. Recurrent severe invasive pneumococcal disease in an adult with previously unknown hyposplenia. BMC Infect Dis. 2015;15:171. https://doi.org/10.1186/s12879-015-0883-2.

69. Iijima S. Sporadic isolated congenital asplenia with fulminant pneumococcal meningitis: a case report and updated literature review. BMC Infect Dis. 2017;17:777. https://doi.org/10.1186/ s12879-017-2896-5.

70. Ugas Charcape CF, Alpaca Rodriguez LR, Matos Rojas IA, Lazarte Rantes CI, Valdez Quintana M, Katekaru Tokeshi DA, et al. Characterisation of computed tomography angiography findings in paediatric patients with heterotaxy. Pediatr Radiol. 2019;49:1142-51. https://doi.org/10.1007/s00247-019-04434-0.

71. Mishra S. Cardiac and non-cardiac abnormalities in heterotaxy syndrome. Indian J Pediatr. 2015;82:1135-46. https://doi.org/10. 1007/s12098-015-1925-x.

72. Ditchfield MR, Hutson JM. Intestinal rotational abnormalities in polysplenia and asplenia syndromes. Pediatr Radiol. 1998;28:303-6. https://doi.org/10.1007/s002470050358.

Publisher's Note Springer Nature remains neutral with regard to jurisdictional claims in published maps and institutional affiliations. 